\title{
La biblioteca universitaria y el desarrollo de la educación superior
}

\author{
Ana Luisa Figueredo Figueredo \\ Maritza de la Caridad Figueredo Matos \\ Carlos Aponte Cabrera
}

Universidad de Granma - UDG, Cuba

\section{ANÁLISIS}

\begin{abstract}
Resumen
En el artículo se aborda la importancia que tiene la biblioteca universitaria para el desarrollo de la Educación Superior, como inagotable fuente de conocimiento que cumple con la misión de hacer accesible la información de sus acervos a su comunidad universitaria. Se destacan funciones que se han llevado a cabo en esta institución desde su surgimiento en el siglo XII hasta la actualidad, con la incorporación de las tecnologías de la información y las comunicaciones. Se evidencia no sólo su relevancia para el apoyo a la docencia y la investigación, sino como una institución determinante en el desarrollo cultural de sus usuarios.
\end{abstract}

Palabras clave

Biblioteca universitaria ; Educación superior ; Investigación

\section{The University Library and the development of higher education}

\section{Abstract}

The article refers to the importance of the university library for Higher Education as a greater source of knowledge. It also deals with the tasks that have been carried out in this institution since its foundation in the XII century up to now. It also states the different technologies for communication. Besides, its relevance is shown not only to support the academic and research process but also to contribute in the users' cultural development.

Keywords

University library ; Higher education ; Academic research

\section{Introducción}

Como en la Antigüedad los hombres sintieron la necesidad práctica, que desarrollaron en la universidad, de apropiarse de una formación que les permitiera ganarse la vida, y cuya formación se viera reflejada en las bibliotecas, en la actualidad, el hombre contemporáneo va transformando cada vez más las oportunidades que la sociedad le va imponiendo con el incontrolable desarrollo que va alcanzando la ciencia y los cambios tecnológicos que tienen lugar en todos los campos del saber. Esto a su vez ha exigido transformaciones en la Educación Superior, reflejado en el nivel de preparación de profesores y estudiantes.

Para cualquier organización e institución contemporánea, el tratamiento de datos e información es sin lugar a dudas de extraordinaria importancia, y las universidades no son la excepción; así como no se puede hablar de estas 
últimas sin hacer referencia a las bibliotecas universitarias, que tuvieron su origen desde la propia creación de las universidades, formando una relación indisoluble (el desarrollo de una trae consigo, indiscutiblemente, el desarrollo de la otra).

La Educación Superior en el mundo entero ha experimentado grandes transformaciones atendiendo al desarrollo alcanzado en la ciencia y las tecnologías de la información y las comunicaciones, así como en las necesidades de los hombres que hacen ciencia.

Para nadie es un secreto que cada día se incrementa a escala mundial el número de jóvenes que optan por un título de nivel superior, demanda que surge impuesta por el propio desarrollo adquirido por la sociedad. Con esto se ha dado también el incremento de los servicios que se ofrecen en las bibliotecas universitarias.

Como resultado del desarrollo alcanzado en las tecnologías de la información y las comunicaciones ha sido necesario reorientar las líneas ha seguir ganando en cantidad y calidad de los servicios, y no apartarse de lo que sucede en el resto del mundo, pues la información ha tenido un papel determinante en la vida del hombre desde sus actividades más elementales hasta las más complejas.

Con el presente artículo se persigue como objetivo: Destacar la importancia de la biblioteca universitaria en el desarrollo del proceso docente_educativo y la investigación en la universidad a través de los servicios que ofrecen sus profesionales de la información.

\section{Analisando conceptos}

En el genuino sentido etimológico del vocablo, biblioteca significa guarda o custodia de los libros.... Hoy se expresa indistintamente con esta palabra, además del armario para depositar los volúmenes, el local o edificio, la institución como entidad de lectura pública y finalmente la colección de obras análogas o semejantes entre sí, que forman una serie determinada (Mesa B y Vega O p.11).

Las bibliotecas universitarias son aquellas que: "Cumplen con la función de hacer accesible la información de sus acervos a la comunidad universitaria y constituye un importante elemento de apoyo a la docencia y a la investigación". (Rojas J p.26)

Poco a poco ha ido cambiando la concepción de que la biblioteca es un local donde se guardan libros. Esto estuvo impulsado, en gran medida por el rápido incremento en el número de publicaciones, sobre todo en la esfera científica y a la aparición de la documentación e el siglo XX.

Es importante destacar la necesidad de aprovechar sus espacios para la promoción de la cultura nacional y universal a través de sus acervos. Según Florence Blakey, en las grandes bibliotecas universitarias, aparte de la función primaria de evacuar consultas, las responsabilidades que tenían la mayoría de los departamentos de referencia incluían lo siguiente:

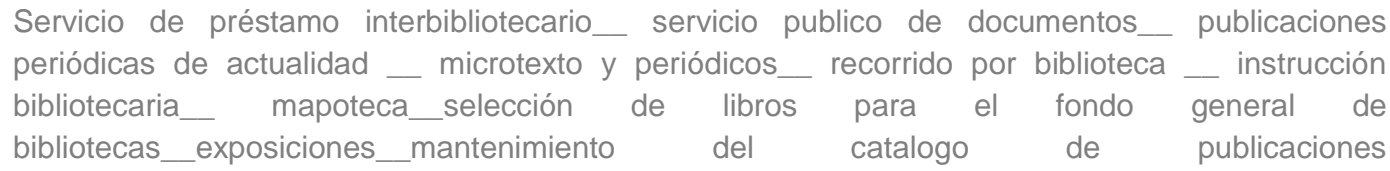
seriadas__procesamiento de tesis y disertaciones_supervisión de salones de lectura temáticos o departamentales__ mantenimiento y servicio de ficheros especiales; es decir, ficheros en el campo de las relaciones humanas y publicaciones rand, repertorios telefónicos, catálogos universitarios etc. Expedición de permisos del uso de los servicios bibliotecarios a visitantes_contribución a publicaciones bibliotecarias o preparación de las mismas_mantenimiento de ficheros internos para usos departamentales indización, recortes de prensa y mantenimiento de ficheros verticales. (citado por Terry M, p.9)

Actualmente entre las funciones de la biblioteca continúan existiendo: reunión, organización, representación, diseminación y uso de los documentos, sin embargo, ya no se limita solamente a los documentos tradicionales (libros, revistas, periódicos, etc.), sino que comparten el espacio con documentos en otros tipos de soporte que van 
adquiriendo cada vez mayor fuerza, como los documentos electrónicos, cuyo estudio ha sido tratado en varios números de la Revista Ciencias de la Información.

En todo el mundo son muchas las bibliotecas que realizan un trabajo esmerado en el tratamiento de aquellos documentos que no son frecuentes encontrar en estas instituciones de nuestra localidad. Estas son en su mayoría nacionales, universitarias, especializadas y públicas.

Las constantes transformaciones que tienen lugar en los campos sociales, políticos, económicos y culturales exigen de las bibliotecas universitarias que estén al tanto de los cambios tecnológicos y no "darle la espalda" a lo que está teniendo lugar, sino que se deben anticipar y adaptarse a estos.

Estas bibliotecas están dirigidas a apoyar los programas educativos y de investigación en las universidades, a lo que ponen en función sus colecciones y diseño de sus servicios. Sus usuarios potenciales son los profesores y estudiantes de la universidad. Sus procesos están en función de facilitar el acceso y uso de la información sea cual fuere el formato en que se encuentren los documentos.

Sus funciones varían en dependencia del ambiente en el cual se encuentren inmersas, independientemente de que en uno u otro caso, son un factor clave en el desarrollo cultural de los pueblos. Es por esto que muchos autores plantean que deben mantener un constante intercambio con el ambiente al cual pertenecen.

Sus colecciones deben corresponderse con las especialidades existentes en la universidad en cuestión, así como deben incluir bibliografías que tributen a elevar la cultura general integral de sus estudiantes y profesores. Pueden estar formadas, además, por los más diversos títulos, que estarán en correspondencia con el nivel de desarrollo que alcance la universidad. Son muy reconocidas en estas instituciones las obras de referencia: atlas, cronologías y efemérides, diccionarios, manuales técnicos, anuarios, enciclopedias generales y especializadas, biografías, bibliografías, etc. Las donaciones juegan un papel importante como una de las vías de adquisición de sus fondos. Su desarrollo se debe en gran medida al enriquecimiento de la enseñanza en general y de la superior en particular, así como a la inserción de nuevos programas.

Con la orientación de las universidades a la investigación, las bibliotecas se convirtieron en un pilar indispensable de la universidad. Para enfrentarse a este reto estas tuvieron que darse a la tarea de: incrementar y actualizar sus fondos, modificar sus horarios de prestación de servicios, crear nuevos servicios, incrementar el número de profesionales de la información, intensificar la preparación de sus profesionales, incrementar el número de materiales no librarios en sus fondos, establecer vínculos con instituciones afines.

Desde hace ya algún tiempo el hombre se percató que es imposible referirse a la docencia y la investigación en las universidades, obviando los servicios que se brindan en las bibliotecas universitarias para suministrar la información adecuada a través de sus recursos humanos. Algunos de estos servicios son: préstamo externo e interno de documentos, préstamo interbibliotecario, difusión selectiva de información, referencia, educación de usuarios.

A estos servicios que son los más tradicionales se unen otros a la altura de las exigencias actuales, que según Magán J son:

- Análisis documental del contenido de la documentación primaria local con inclusión de resúmenes.

- Establecimiento de entrada a los catálogos más flexibles y pertinentes, por lo que se requiere el uso de la indización en lugar de los encabezamientos de materia.

- Elaboración de boletines electrónicos con lo cual se eliminan los costos de edición y distribución de los boletines sobre papel.

- Elaboración de bibliografías orientadas hacia grupos de usuarios concretos cuyas necesidades informativas hayan sido establecidas previamente.

- Actuaciones propias de consultores de información. 
- Orientación respecto a las fuentes de información más pertinentes según las necesidades de los distintos grupos de usuarios concretos en el caso de investigadores o gestores. (citado por Vizcaya D, p.114)

Debido a las actividades docentes e investigativas que se llevan a cabo en las universidades y en las que el factor tiempo tiene una alta prioridad, en las bibliotecas universitarias se debe trabajar aún más en cuanto a la relevancia y pertinencia de la información que se brinda a cada usuario, facilitando un uso adecuado de esta y tratando de llenar las expectativas que tienen dichos usuarios respecto al sistema.

Sin lugar a dudas se puede decir que la aparición de las computadoras ha significado para nosotros, lo que la creación de la imprenta por Gutenberg en el siglo XV para la humanidad, al acercar los libros un poco más a las masas y con esto aumentar la lectura. Como se planteó anteriormente, en las bibliotecas ya no sólo encontramos libros impresos sino que comparten el mismo "recinto" una gran variedad de documentos en diferentes formatos: diapositivas, casetes, discos de placa negra, pinturas, mapas, medallas, monedas, tarjetas postales, microfilmes, revistas, películas, cintas magnéticas, documentos electrónicos, etc. Al aparecer documentos en diferentes soportes, han tenido que nuevas alternativas atendiendo a las características y particularidades de cada tipo de documento.

En un principio, sobre todo en las bibliotecas de las universidades de América Latina no se concebían las computadoras como herramientas para el procesamiento de su información o para la recuperación de la misma.

En la contemporaneidad, las revoluciones tecnológicas que están teniendo lugar requieren de las bibliotecas una reorientación de sus funciones, dejando atrás aquello de que son vistas como meros almacenes de libros. El propio desarrollo de la humanidad ha exigido la evolución de los soportes en que se representa la información, desde la tableta de arcilla, hasta los medios electrónicos.

Desde hace algunos años se puede apreciar que en las bibliotecas universitarias es cada vez menor el tiempo que se emplea para las labores tradicionales de catalogación y clasificación y se encamina el trabajo hacia el desarrollo del análisis documental.

La visión del bibliotecario como salvaguarda de libros ha cambiado por la de especialista en información. No han desaparecido las actividades tradicionales de las bibliotecas: selección, adquisición, procesamiento, almacenamiento, recuperación y diseminación, ni desaparecerán, sino que ha habido cambios significativos en la manera de realizarlas.

No sirve de mucho que una biblioteca cuente con lo último en tecnología, valiosas colecciones, así como buenos recursos materiales y financieros si no posee un personal preparado y calificado, informado de lo que sucede a su alrededor, adapatado al cambio en un mundo en el que lo que hoy es, mañana no existe.

La función del bibiotecario con el paso del tiempo, aunque sin perder su esencia, ha sufrido importantes cambios, como se planteaba anteriormente, que se ven reflejados desde la selección de un documento hasta su diseminación. Hoy lo podemos ver más que como un sistematizador, como un facilitador de información en las universidades, dando apoyo a las actividades docente, académica e investigativa.

En las bibliotecas universitarias ya no sólo encontramos graduados de la carrera de bibliotecología, sino que podemos encontrar especialistas en otras materias como biólogos, químicos, informáticos, etc.

Muchos especialistas consideran que nos adentramos en una época en la que los usuarios son cada vez más independientes en cuanto al uso de intermediarios de la información (bibliotecarios, archivistas, documentalistas, museólogos, etc.), sin embargo, pasará bastante tiempo en el que el trabajo de estos especialistas será necesario en un mundo en el que la infoxicación (exceso de información) aumenta a un ritmo increíble, es decir, con demasiada rapidez.

Según Currás las funciones bibliotecarias se concentran en tres grandes grupos:

- Investigación: En el descubrimiento de nuevos métodos, en el diseño de sistemas y herramientas que se ajusten a los actuales requerimientos de los usuarios,

- Gestión: En la dirección de sistemas de información y como encargado de organizar, planificar, dirigir y controlar la información y su flujo en las organizaciones. 
- Difusión: En la prestación de servicios y en la formación de usuarios.

Debe ser capaz de vincular de manera eficiente la labor desarrollada en la biblioteca con el de los restantes departamentos de la universidad. (citado por Ponjuán G, p.54)

El mundo actual demanda de personal competente capaz de conocer las necesidades de sus usuarios y satisfacer las mismas. Estos profesionales no deben ni pueden apartarse de los especialistas de otras profesiones sino que tienen que acercarse cada vez más y crear equipos de trabajo que les permita enriquecer su labor.

Hoy el bibliotecario debe ser capaz de facilitar el uso efectivo de la información y saber seleccionar adecuadamente dentro de una gran cantidad de documentos. El profesional de la información en las bibliotecas universitarias debe estar al tanto de las necesidades de los usuarios (alumnos y profesores) que constituyen la razón de ser de la institución. Por esto es importante que se creen mecanismos de retroalimentación, ya que estas necesidades pueden variar y pasar desapercibidas si no se establece una adecuada interacción usuario/bibliotecario.

Las bibliotecas universitarias a las que nos enfrentamos hoy requiere de profesionales con imaginación, que puedan tomar decisiones propias, donde no haya lugar para la implementación de malos servicios y que como Taylor planteara, tenga: "...Visión, habilidad política y de comunicación, capacidad de llevar a la práctica los planes, tenacidad, persistencia, paciencia, flexibilidad y talento para el trabajo en equipo y para concertar alianzas, actitud de apertura ante los cambios y de aceptación de retos, creatividad y energía" (citado por Rojas J, p.28)

\section{Conclusiones}

Las bibliotecas universitarias juegan un papel determinante en el desarrollo de los procesos docente_educativo e investigativo en las universidades, por lo que sus funciones están encaminadas a facilitar el acceso y uso de la información sea cual fuere el formato de los documentos que reúne. Contribuyen, además, a la formación profesional de los estudiantes universitarios, por medio de sus servicios de información, donde se manifiesta en todo momento la vinculación de los documentos tradicionales con las tecnologías de la información y las comunicaciones, en un espacio donde confluyen el aprendizaje y el entretenimiento para un bien común: la formación integral de sus usuarios.

\section{Bibliografía}

Blakey, F. (2003). Perceiving Patterns of Referente Service: A study. En: Terry, M. Referencia. Selección de lecturas. La Habana: Editorial Félix Varela.

Currás, E. Panorama Sistémico del profesional de la información en el año 2000. En: Ponjuán, G (2004). Sistemas de información: Principios y aplicaciones. La Habana: Editorial Félix Varela.

Escobar, H. Historia de las bibliotecas. La Habana: Editorial Félix Varela, 2006. p. 179. Primera parte.

Magán, J. La descripción bibliográfica hoy : sugerencias para el aprovechamiento de las nuevas tecnologías. En: Vizcaya, D (2004). Fundamentos de la Organización de la información: selección de lecturas. La Habana: Editorial Félix Varela.

Mesa, B y Vega, O. (2002). Bibliotecología. La Habana: Editorial Félix Varela.

Rojas, J (2006). Diseño de servicios de información: selección de lecturas. La Habana: Editorial Félix Varela.

Sánchez B. Ciencia, investigación y cultura en la biblioteca universitaria actual. Disponible en: http://bvs.sld.cu/revistas/aci/vol15 1 07/aci16107.htm [Consulta: 11 abril 2009].

Sánchez B. La universalización de la Educación Superior en Cuba: una oportunidad para reflexionar sobre los modelos de gestión en las bibliotecas universitarias. Disponible en: http://bvs.sld.cu/revistas/aci/vol12 2 04/aci13204.htm [Consulta: 11 abril 2009$].$

Taylor, M. Getting it all together: leadership requirements for the future of information services. En: Rojas, J. (2006).Diseño de servicios de información: selección de lecturas. La Habana: Editorial Félix Varela.

Zuluaga J R.. La función cultural del profesional en bibliotecología. En: Rivero A. Una aproximación a la comunicación, la propaganda y la promoción de la lectura. Selección de temas. La Habana: Universidad de la Habana; 1997. 
Biblios La biblioteca universitaria y el desarrollo de la educación superior

\section{Datos del autor}

Ana Luisa Figueredo Figueredo

Licenciada en Bibliotecología y Ciencias de la Información. Máster en Ciencias de la Educación Superior. Profesora instructora de la Universidad de Granma.

afigueredof@udg.co.cu

Maritza de la Caridad Figueredo Matos

Licenciada en Bibliotecología y Ciencias de la Información. Profesora instructora de la Universidad de Granma.

afigueredof@udg.co.cu

Carlos Aponte Cabrera

Licenciado en Bibliotecología y Ciencias de la Información. Profesor instructor de la Universidad de Granma.

aponte@udg.co.cu

Recibido-Received : 2013-02-15

Aceptado-Accepted : 2013-03-30

(c) EY New articles in this journal are licensed under a Creative Commons Attribution 3.0 United States License.
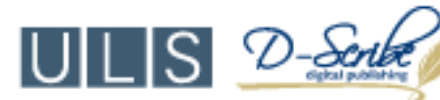

This journal is published by the University Library System of the University of Pittsburgh as part of its D-Scribe Digital Publishing Program and is cosponsored by the University of Pittsburgh Press. 